sued by the wave-fronts. It will be found by those who care thus to apply Professor Airy's results, that the following estimates by Professor Hochstetter are approximately correct.

He makes the mean depth-

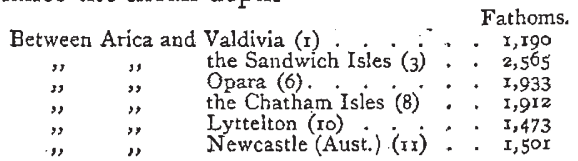

These results are the more valuable, because the Pacific Ocean has not been so carefully sounded as the Atlantic has. And though the progress of the tidal wave has long afforded similar evidence, yet a certain amount of doubt necessarily rests over conclusions drawn from the progress of a wave which is acted upon throughout its voyage across the Pacific by the attractions which gave it birth.

We may add, in conclusion, that on December 23, 18.54, a wave traversed the Pacific from Japan to San Francisco and Diego, or from (4) to the neighbourhood of (2), whose progress, dealt with according to Professor Airy's numbers, showed the mean depth of the sea between Japan and San Francisco to be 2, I 49 fathoms, and between Japan and Diego 2,034 fathoms. These results agree fairly with those which have been deduced by Professor von Hochstetter.

R. A. PROCTOR

\section{A NEW F FORM FOR SCHOOLS}

$A \mathrm{~T}$ the first blush this may seem a trivial subject, but when we consider the immense floating multitude of children who frequent schools, spending at least some 6,000 hours on forms during the time that they are at school, and that their health may be injuriously affected by the use of unsuitable ones, the importance of the sub. ject becomes evident.

Dr. E. H. Schildbach states, in the Gartenlaube, that amongst more than a thousand children whom he examined in several schools at Leipsic, he found only a few who did not show some lateral curvature or deviation of the spinal column, traceablc to the use of improper forms.

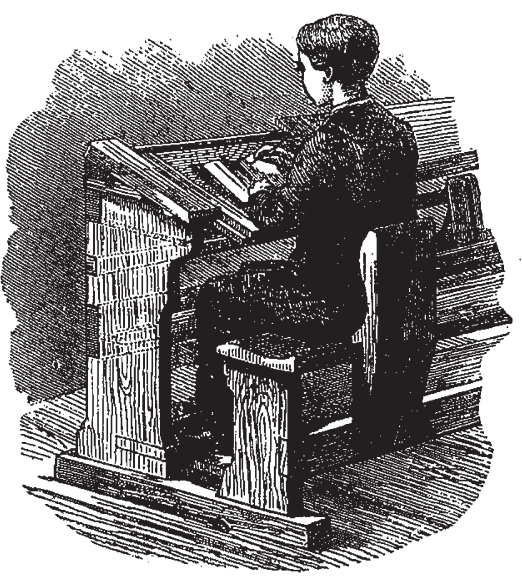

The chief defect in the construction of these forms was the great space between the seat and the table. Seats without backs soon tire out even robust children; they cannot sit upright for several hours together, and after much shifting from side to side, they are constrained to obtain relief by sitting on the very edge of the bench, and resting their arms on the table before them. The position into which they are thus forced is anything but a salutary one. The back is curved, especially in its lower half; the thorax sinks between the shoulders, and chest and stomach suffer a not inconsiderable pressure. To write in this position, one shoulder is raised much higher than the other, and the whole body is twisted unnaturally. With young and growing people the assumption of constrained positions, even for a few hours day by day, soon becomes habitual, and in many cases may lead to real deformity.

Our illustration represents the model form recommended by Dr. Schildbach, invented by Mr. E. Kunze, of Chemnitz, in Saxony, and will scarcely require a detailed description. It will be seen that the table forms an inclined plane without the usual level projection at its upper part. It is divided by cross bars into separate desks, and the boards which form the desks are movable and can be drawn out. A metal button with a lateral motion holds each board in its place, and also fixes it when drawn out. At the top in front are places for inkstands and writing materials, covered by the board when pushed home. Each seat has its separate back, of a shape best calculated to give proper support with the least possible pressure, while it allows the pupil to leave his place by stepping back over the seat without disturbing his neighbour. Underneath the table is a shelf. for books, slates, \&c., and beneath this there is a foot-board, an important provision against cold. The inexpensive character of this form and simplicity of its construction will be apparent to everyone.

\section{THE NOVEMBER SHOOTING-STARS}

$T H E$ earth is rapidly nearing the band of cosmical bodies to which the November star-showers owe their occurrence. Whether we are to witness a display or not depends wholly on the nature of that portion of the band through which we are to pass this year. The portion which gave the great display of 1866 has now passed many millions of miles away on its course towards the orbit of the distant planet Uranus. Nearer to us, but still many millions of miles away, is the part which we traversed in 1867 , when (in America) there was a short but brilliant display of meteors, which would have afforded a yet more stiriking exhibition but for the full moon which dimmed their splendour. In I 868 meteors were seen in every part of the earth, and even, in America, on two successive nights. It is clear, therefore, that the portion of the band then traversed was very much wicler than the part through which the earth had passed in the two former years. But even the part traversed in 1868 is more than five hundred millions of miles away from us now ; and it is difficult indeed to say what may be the character of the portion we are approaching. Most probably it is even wider than the part we passed through in 1868 ; in which case we are sure (if the weather be but fine) to see a display of the November shooting-stars, though the same process of wide-spreading would of course tend to make the display so much the less brilliant.

It must be remembered that it will be absolutely useless to look for the meteors much before midnight of November 12-I3 and of November I3-14. England does not come round to the exposed hemisphere of the earth-that is, to the hemisphere which is bearing directly through the meteor-band-much before ten o'clock in the evening; and she does not turn her full face, so to speak, towards the meteors before midnight. From that time until ten in the morning the rain of meteors is directed upon England without intermission, though no sign of the falling stars can be noticed after sunrise.

Our neighbours across the Channel propose to send observers to the shores of the Mediterranean, there to watch the meteors under more favourable circumstances than in more northern latitudes. Although we already know the principal conditions under which the meteors move, yet all observations directed to the determination of the size, colour, and constitution of these interesting bodies, will be well worth the making. The comet-nucleus 
of the system has now travelled nearly a thousand millions of miles away since in 1866 he passed his perihelion; and it will be interesting to learn whether the character of his train of followers is at all dependent on their distance from him.

\section{R. A. PROCTOR}

[To this note we add the following extract of a letter from Mr. Hind, which appeared in the Times of Tuesday.ED.]

"The elements of the orbit in which the November meteors revolve are as follow, according to the last calculations of the Italian astronomer Schiaparelli, founded upon the accurate data obtained during the grand display in $\mathbf{1} 866$. Heliocentric longitude of perihelion or of the point nearest to the sun, $56^{\circ} 26^{\prime}$; crosses the plane of the earth's path from north to south in $51^{\circ} 28^{\prime}$; inclination of orbit to the plane of the earth's path, $I 7^{\circ} 45$; eccentricity of orbit, 0.9046 ; distance from sun in perihelion, 0.9873 (the earth's mean distance being taken as unity); semi-axis major of the orbit, 'I0'340, similarly expressed; period of revolution, 35.25 years; motion retrograde or opposite to that of the earth. At its nearest approach to the sun the orbit is therefore situate close to the earth's, while in aphelion it is not far distant from that of Uranus. It is well known that these numbers are almost identical with those applying to the orbit of the first comet of 1866 , and I have lately ascertained beyond reasonable doubt that the comet of 1366 , which became visible three days after the memorable meteoric exhibition in October of that year, when 'there was a movement of the stars such as men never before saw or heard of,' and 'those who saw it were filled with such great fear and dismay that they were astounded, imagining they were struck dead, and that the end of the world had come,' as the exaggerated language of the time has it, also moved in a similar orbit. It was, doubtless, visible during the shower on the confines of Ursa Major and Leo Minor, but the Chinese did not perceive it till three nights later. It was not seen in Europe."

\section{- - A PENNY SCIENCE CLASSES}

$\mathrm{N}$ opening the session of the Birmingham and Midland Institute recently, the. President, Mr. Charles Dickens, referred to the " penny system" of instruction as "one of the most remarkable schemes ever devised for the educational behoof of the artizan ; " and as this system, so far as we know, is adopted only at the Birmingham institution, we have made inquiries respecting its working there. We learn that, soon after the opening of the Science Classes in 1854 , the teacher, Mr. Williams, observing that after a few terms the attendance fell off, suggested the establishment of Penny Lectures, as introductory to systematic scientific instruction. This plan answering well, an arithmetic class was commenced by $\mathrm{Mr}$. Rickard, to which students were admitted on payment of one penny at the door. Subsequently other classes were started un the penny system, and now among others even chemistry and physical geography are taught in penny lessons. The chemistry class was formerly conducted on the quarterly plan, the fee being 35 . per term of twelve lessons. Though the fee was low, the attendance seldom reached more than 40 or 50 per night; while since the introduction of the penny system it is about roo during the winter months. The persons attending the class are of all grades of society; but since the change to the penny system the proportion of artizans has much increased. We are not surprised at this, in fact it is what we should expect. . The wage-paid class receive their earnings weekly, they pay their rent weekly, their "settlings". are made weekly, and their books they take in in weekly numbers. It is not to be surprised at, then, that a science class in which the fee is paid weekly should be popular with artizans. Where the fee is so low as one penny we do not see how a class can pay ; but such institutions as that of Birmingham are not intended, and never were intended, to pay in a commercial sense. The promoters and subscribers are only too pleased to find their efforts successful in inducing attendance at the classes. Viewed in this way we believe the penny system to be the best of any; and the Birmingham and Midland Institute desterves all honour for having introduced it.

\section{LETTERS TO THE EDITOR}

[The Editor does not hold hinnself responsible for opinions expressed by his Correspondents. I

\section{Scientific Education at Cambridge}

I NOTICE a paragraph at page 26 of NATURE, in which, while the facts are correct, a wrong inference is drawn from them. Two gentlemen at Cambridge have been appointed to lecture on subjects in natural science, and one of these has been appointed to lecture on electricity, magnetism, and botany. These facts are correct, and your informant congratulates the University on the increased desire for instruction in these subjects manifested among the members of the University, but says, "is the number of men in the University competent to teach them so small, that it has been found necessary to "entrust electricity and botany to the same lecturer?" But the real state of the case is, that in the University there is not a want of those able to teach Natural Science, but a want of those desiring to learn it. In fact, there are so few who want to learn these matters of science, that we cannot afford to pay, and have no need to appoint, more than one man to do the work. The lectures which we. have in these subjects are insufficiently attended. The University is not behind the age in the power of teaching these matters, but before the age. If there had been many people coming here desiring to be taught certain subjects, and we had been unable to supply that teaching, we should in that have been behind the age. But we are offering teaching which those to whom we offer it have not yet learned, or do not yet care, to appreciate: I am not saying that we have the power of showing all the wonders that the astronomers of the present day can watch with their spectroscopes. We are not well supplied with apparatus; but our want of it does not arise so much from the inefficiency of our teachers as from the apathy of those who are taught. We have quantities of excellent apparatus exhibited and lectured about daily by several of our professors well able to deal with these matters, and yet these lectures are taken advantage of by only a very few. If these lecturerooms were once crowded, the University would only be too happy, and would immediately have at its command abundant means to increase the staff of competent teachers. We have in fine more than a sufficient number of people who can teach, and, what is more, are willing to teach, natural science, if only there are those who care to be taught.

But it would seem as if the classes, from whom the University is recruited, were behind the age in their desire to be taught these matters ; for if we turn away from the University we find a very different state of things, There can be no doubt that throughout England there is "a "great"demand for scientific education. - This demand exists more or less among all classes, and it exists among the working-men of this country to an extent which could hardly be believed by those who have not had some experience in the matter. Among these there is a great desire for scientific instruction, and there is no one to supply it.

The case of the "University is exactly reversed. There are I, 500 undergraduates at Cambridge, and there are more men able to teach them science than there is any need for. But look to the non-university classes of England; there are a thousand times that number eager to learn, and not all the men who come forward to teach them unite the qualifications of willingness and of competency. That there is a great demand for scientific education; - and that not of a desultory kind, among vast numbers of the various uneducated classes of England, is a most certain fact. If anyone doubts this, let him go to some of our great workshops, and let him give. a series of careful lectures on some scientific subject, and I will venture to say he will be simply astonished at the numbers who will come. I have seen crowding to a weekly lecture on Astronomy, or on Light, hundreds of workmen who had all been working for at lea' ten hours 